\title{
BMJ Open Gendered lived experiences of marriage and family following exposure to chemical warfare agents: content analysis of qualitative interviews with survivors in Halabja, Kurdistan-Iraq
}

\author{
Faraidoun Moradi (D) , ${ }^{1}$ Fazil Moradi, ${ }^{2}$ Mia Söderberg, ${ }^{1}$ Anna-Carin Olin, ${ }^{1}$ \\ Mona Lärstad ${ }^{1,3}$
}

To cite: Moradi F, Moradi F, Söderberg M, et al. Gendered lived experiences of marriage and family following exposure to chemical warfare agents: content analysis of qualitative interviews with survivors in Halabja, Kurdistan-Iraq. BMJ Open 2020;10:e034277. doi:10.1136/ bmjopen-2019-034277

- Prepublication history for this paper is available online. To view these files, please visit the journal online (http://dx.doi org/10.1136/bmjopen-2019034277).

Received 12 September 2019 Revised 29 August 2020 Accepted 01 September 2020

Check for updates

(C) Author(s) (or their employer(s)) 2020. Re-use permitted under CC BY-NC. No commercial re-use. See rights and permissions. Published by BMJ.

For numbered affiliations see end of article.

Correspondence to Dr Faraidoun Moradi; faraidoun.moradi@gmail.com

\section{ABSTRACT}

Objective To study gendered experiences of the longterm effects of a chemical warfare agent (CWA; sulfur mustard).

Design Qualitative face-to-face semi-structured in-depth interview study using content analysis approach with thematic analysis and anthropological inquiries.

Setting The city of Halabja in the Kurdistan Region of Iraq. Participants Survivors of CWA ( $n=16$, female:male 10:6, mean age 45.5 years (range 34 to 67)) with lung damage diagnosis and with a range of sociodemographic variables. Results Latent content was expressed as: To get or not to get married? Two categories-social abandonment and uncertain marriage-emerged as expressions of the manifest content. The majority of the participants showed uncertainty as a central concern that affects all decision-making in their private and social life. Uncertainty over marriage and family were huge, corresponding to their fear of giving birth to children with congenital birth defects. Exposure to CWAs was conceptualised in terms of stigmatised illnesses, and consequently resulted in Ioneliness and social isolation, leading to negative impacts on other aspects of professional and social life. The results demonstrated a gendered pattern: CWA-exposed women were more affected psychosocially than CWA-exposed men. More CWA-exposed women were unemployed, divorced or single, or lived under vulnerable circumstances compared with men.

Conclusion Survivors of CWA exposure have developed a sense of gendered uncertainty around getting married and building a family. Sulfur mustard-exposed women, in particular, long to be desired in the community as they face social exclusion. Survivors should be provided evidence-based consultancy to optimise their decisionmaking around marriage and other social and family challenges.

\section{INTRODUCTION}

The widespread employment of chemical warfare agents (CWAs), including sulfur mustard (SM), dates back to World War I. Since then, other CWAs, such as tabun and
Strengths and limitations of this study

- The participants were civilian survivors of sulfur mustard exposure who varied in age and gender, thus providing a range of lived experiences.

- Interdisciplinary study: the research included medical, anthropological and psychological analysis of face-to-face semi-structured in-depth interviews using a content analysis approach with thematic analysis that is weaved together with long-term anthropological inquiry into al-Anfāl genocide, ensuring results of high quality and validity.

- The first author's occupation as a physician and sociocultural and linguistic competence (Sorani Kurdish) promoted trust, further enhancing the interdisciplinary analysis.

- The participants came from a war-ravaged environment, meaning that their cumulative traumatic experiences may have affected the outcome.

- The interviewer was male, and his gender might have hindered women interviewers' narrations of certain lived experiences.

sarin, have been employed by both nation states and terrorist organisations. ${ }^{1-4}$ The Iraqi Ba'ath state's al-Anfāl genocide (1987 to 1991) targeted Kurdish political organisations and the civilian population, including religious minorities such as Yazidis (Êzîdîs), Christians and Kāka'is (Yarsan) in the then Kurdish Autonomous Region of Iraq. CWAs such as SM were used on a large scale. ${ }^{5-8}$ As one of the main targets, the town of Halabja, was bombarded by a cocktail of chemicals on 16 March 1988, and almost 5000 people, including many children, died that day as a result. ${ }^{9}$ Today, around 6000 CWA-exposed persons with multiple health complaints live in the Kurdistan Region of Iraq (KRI).

Although previous studies have demonstrated the medical and psychological 
long-term effects of CWAs exposure, ${ }^{1310}$ existential conditions and social dimensions, such as gendered effects, have scarcely been studied. ${ }^{11-14}$ Apart from long-term damage to the eyes, skin and respiratory system, ${ }^{15} 16 \mathrm{SM}$ is scientifically categorised as a teratogenic, that is, a substance that causes birth defects and, in this case, is similar to nitrogen mustard-a known teratogen. In addition, SM is also socially experienced with negative effects on offspring in Halabja. The stigma associated with CWAs exposure has left SM-exposed women, in particular, to face inevitable existential consequences. ${ }^{12} 17$

In addition, some studies have shown that SM can disrupt sex hormones, and induce a variety of structural and functional disorders in the male reproductive system post exposure. ${ }^{18} 19$ How these changes affect fertility among those who survived SM exposure is, however, still unclear. $^{19-21}$ Moreover, in a study among SM survivors (males and females) almost 15 years after exposure to SM, no increased infertility was observed. ${ }^{22}$ So far, there is no direct study on the effects of SM on the female reproductive system and the ability to bear healthy children.

This interdisciplinary, qualitative study aimed to examine the lasting effects of CWAs on marriage and family among civilian survivors after exposure to $\mathrm{SM}$ in the city of Halabja. As social challenges have increased among survivors over the years, ${ }^{12} 14$ it is increasingly urgent to examine how CWAs shift human experiences and relations to marriage and family.

\section{METHODS}

\section{Study design}

A cross-sectional interdisciplinary qualitative research method with an inductive thematic approach was performed, using an interview guide that has previously been published, to guide the semi-structured in-depth individual interviews. ${ }^{172}$ This interviewing technique is recognised for its ability to identify high priority issues for interviewed individuals. ${ }^{24}$ This method allowed participants to talk openly about their lived experiences. This especially benefited women since they have fewer opportunities to talk about their lived experiences outside a research context in this community. We employed openended questions regarding participants' professional and social lives (ie, family, marriage, health, work and financial situations, hopes and fears) in order to critically assess the larger context of participants and their relationships.

\section{Methodological orientation}

Marriage and family experiences varied greatly because they are highly influenced by sociocultural factors. This experience can also vary from individual to individual based on family history, gender and age. The present study is a qualitative content analysis of lived experiences of marriage and family following exposure to CWAs. As such, it is suitable for inductive thematisation of data to get a description of the phenomenon at hand and anthropological inquiry to explore the living conditions of women and men from a social-historical perspective.

\section{Study setting and participants}

The data were collected as part of a PhD project to assess the biopsychosocial impacts of exposure to SM among civilian survivors with respiratory symptoms in Halabja. The procedure for sampling, recruiting and collecting data has previously been reported in detail. ${ }^{17}$ In brief, the study was conducted in Halabja and we used purposive sampling to gather a heterogeneous group with varied sociodemographic variables. The inclusion criteria were previous assessment by a medical committee leading to registry as 'CWA exposed with established lung damage'. Overall, $90 \%$ of SM victims develop lung complications. ${ }^{25}$ Exclusion criteria were severe illness or long-term oxygen therapy.

\section{Patient and public involvement}

Patients or the public were not involved in the design or conduct or reporting or dissemination plans of our research.

\section{Data collection}

The data comprised of 16 face-to-face (female:male (f:m) 10:6) interviews conducted in October 2016 by the first author (Faraidoun) - a doctoral student, physician and pharmacist with experience in qualitative studies. The interviewer had no previous contact with the participants. The interviews were held in the Sorani Kurdish language in a relaxed environment, such as the respective offices of non-governmental organisations of CWAs survivors-the Halabja Chemical Victims' Society and the Halabja Glory Organisation-or the participant's home, depending on the participant's preference. Data saturation was achieved with 16 interviews, as no new information emerged in the last interview. Interviews were taped and had a mean duration of $37.5 \mathrm{~min}$ (range 30 to 45 ). They were later transcribed and translated into English by a qualified translator. The first and second authors then validated the material by comparing the transcribed data to the taped interviews. In addition to their interview, each participant completed a questionnaire including demographic information.

\section{Analysis}

The analysis was performed between March and October 2018. A qualitative content analysis was applied to the manifest and latent content of the data and an anthropological inquiry went beyond single accounts to compare the accounts within the social-historical context. ${ }^{23}$ The interviews were studied separately by all members of the research team so they could familiarise themselves with the data and obtain a preliminary overview. The first author was primarily responsible for coding the data in close collaboration with the second author, a common approach in long-term anthropological inquiry that covered the whole of al-Anfāl genocide, including Halabja, by the second author of this study between 2012 and 2020. ${ }^{1326}$ Prior to condensation, the generated codes were discussed by the research group until consensus was reached. The codes were then condensed, citations were 
Table 1 Summary of demographic variables. Unless otherwise specified, values are given as $\mathrm{N}(\%)$

\begin{tabular}{|c|c|c|c|}
\hline Variables & Total N (\%) & Male N (\%) & Female N (\%) \\
\hline Mean age (range), years & 45.5 (34 to 67 ) & 44.7 (34 to 67 ) & 46.8 (35 to 61$)$ \\
\hline Sex & $16(100)$ & $6(38)$ & $10(62)$ \\
\hline Married & $8(50)$ & $6(100)$ & $2(20)$ \\
\hline Single & $4(25)$ & $0(0)$ & $4(40)$ \\
\hline Widowed & $1(6)$ & $0(0)$ & $1(10)$ \\
\hline \multicolumn{4}{|l|}{ Education } \\
\hline Elementary school or lower & $9(56)$ & $3(50)$ & $6(60)$ \\
\hline High school & $4(25)$ & $2(33)$ & $2(20)$ \\
\hline University studies & $3(19)$ & $1(17)$ & $2(20)$ \\
\hline \multicolumn{4}{|l|}{ Occupation } \\
\hline Retired & $1(6)$ & $0(0)$ & $1(10)$ \\
\hline \multicolumn{4}{|l|}{ Tobacco consumption } \\
\hline Non-smoker & $15(94)$ & $6(100)$ & $9(90)$ \\
\hline Former smoker & $1(6)$ & $0(0)$ & $1(10)$ \\
\hline \multicolumn{4}{|l|}{ Children } \\
\hline None & $4(25)$ & $0(0)$ & $4(40)$ \\
\hline One to two & $7(44)$ & $2(33)$ & $5(50)$ \\
\hline Three to four & $4(25)$ & $3(50)$ & $1(10)$ \\
\hline Seven & $1(6)$ & $1(17)$ & $0(0)$ \\
\hline
\end{tabular}

produced and interconnected codes were sorted into different categories. The categories and subcategories were discussed and refined within the research group and presented as expressions of manifest content. In contrast, the latent content was conceptualised as an ovarching theme to allow it to go beyond individual accounts and place them in social context. The computer software NVivo (QSR International Pty Ltd, V.10) was used to sort the quotations. ${ }^{27}$ The Consolidated Criteria for Reporting Qualitative Research (COREQ) 32-item checklist was used to report the results. ${ }^{28}$

\section{Consent}

The participants were informed of the purpose of the study, the researcher's occupation and background, and were told that participation in the study was voluntary and that their privacy would be assured. To assure anonymity, all the transcribed data were anonymised.

In March 2019, each participant received a copy of his/ her transcribed interview in Kurdish for comments and gave written informed consent.

\section{FINDINGS}

Demographic characteristics of the full sample have been previously published. ${ }^{17}$ The respective characteristics of female and male participants are presented in table 1.
The mean age was f:m 47:45 years. Marital status was married (f:m 2:6), single (f:m 4:0), divorced (f:m 3:0) and widowed (f:m 1:0). Education level was elementary school or below (f:m 6:3), high school (f:m 2:2) and university (f:m 2:1). Occupational status was employed (f:m 2:3). There was no occurrence of alcohol or tobacco consumption.

The results show that post-exposure lived experiences include a variety of concerns about marriage, family and social life. Within this context, we divided the manifest content into two categories: social abandonment and uncertain marriage. The latent content was expressed as: to get or not to get married? This uncertainty was a central concern in an exposed individual's professional and social life, affecting all decision-making from getting married, forming a family and having children, to sustaining the family financially, having satisfactory sexual relationship and being an active member of society (figure 1). A module has been created to demonstrate the unfolding impact of SM exposure on family, marriage and social life in relation to health deterioration (figure 2 ).

\section{Social abandonment}

All SM survivors in the current study, especially exposed women, experience stigma and social abandonment in their everyday lives. In Kurdistan, and Iraq as a whole, 


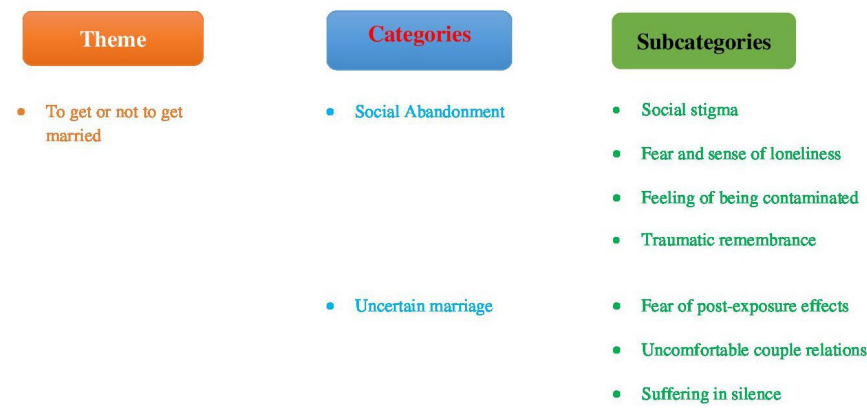

Figure 1 Schematic representation of manifest and latent content: theme, categories and subcategories.

marriage and having children mark the beginning of adult life. Exposure to SM has minimised participants' prospects of getting married and building a family, which is the basic ground for a sustainable social life. All SM-exposed single women (25\% of the participants) expressed concerns about present and future social exclusion, and substantial loneliness. Reduction in their social activities further contributed to the breakdown of relations between the participants and their social community and caused a sense of undesired loneliness.

I have lived in an uncomfortable condition ever since the bombardments. So, this makes you not think about anything. Sometimes you feel you are powerless and forced to stay at home and in bed with an infection. Just like someone who gets old and would feel the burden of age and that no one would care about her. FI:7

The survivors pointed out how post-exposure effects and complications have led to social stigmatisation and how it affects women differently. The stigma could be related to the diagnostic stamp of CWAs exposure in addition to the others post-exposure symptoms (eg, respiratory problems, symptoms of infection or visible skin scars).

Girls are only [worried] about one thing, which is marriage. I have felt that it's very difficult. For example, you love someone but people around him

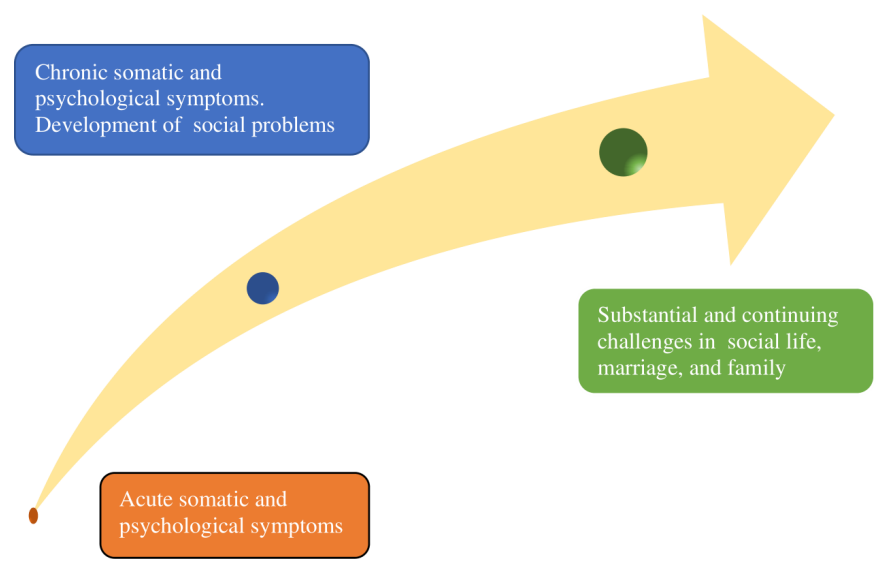

Figure 2 Shows complexity of survivors somatic and psychological complaints, and development of challenges in social and private life. wouldn't let him [marry you]. Why? Because the girl is a survivor of chemical weapons. FI:9

When they know you're ill because of the SM, they look at you with disgust... you are different from them. They think wrongly about these things. And about marriage, you're afraid that people... I don't know how to say that. FI:9

They (people in Halabja) consider you like another kind of human being. I mean they think of us, the wounded, as some creatures that are only awaiting gradual death. FI:15

Men often cancel engagements as soon as they hear that the woman they want to marry has been exposed to CWAs. SM-exposed unmarried girls commonly experience abandonment, entailing not only loss of family and marriage but also loss of social life.

It has even happened that we reached the engagement phase, just about to finish all the arrangements. I think someone else had told him that I had this chemical illness; because of that, he withdrew. I really got sad.... I have, therefore, rejected many men who proposed to marry me. I'm afraid of experiencing the same story over and over again. I cannot stop thinking about my earlier experiences with men who just rejected me, as if I was nothing. FI:9

Some women participants had been married but divorced because their health deteriorated after exposure to CWAs, and they reported traumatic memories of abandonment.

They [the man's family] divorced me because of my illness. They said "we can't take you that often to this and that doctor"... I became worse.... They wouldn't take me to any doctor or buy me any medicine. Then they divorced me. I would not want to marry someone else again and experience the same treatment again. No way. It's better to hold on to my integrity. FI:12

\section{Uncertain marriage}

Almost all married participants reported that they felt uncertain about whether their marriage would survive. Survivors' problems have become more complicated over time due to increased uncertainties over their psychosomatic symptoms, which could result in physical impairment, financial insecurity and fear of effects on children, in addition to long-term family and social consequences. These uncertainties may be different in men and women. Female survivors experience fear of miscarriage or birth defects and worry that they are perceived as unable to take care of their family or home. Male survivors suffer from the uncertainty of death that follows the exposure to CWAs and their fundamental role in the family.

I'm actually worried and think often about my marriage. I tell myself, "I shouldn't have married in this 
life." Because we, wounded people, shouldn't get married because you [the exposed individual] make children. I'm sure whether it is today or tomorrowthis is the work of God-it will kill you certainly. (male interviewee (MI:13))

Conventionally, in the KRI, the man proposes marriage. Thus, SM-exposed men have more control and fewer obstacles to getting married, although they operate under a similar stigma as affected women. All male participants were married, while only $20 \%$ of female participants were married. Most of the SM-exposed men mentioned that deterioration of their health made them wonder often if it was the right decision to get married and have children. Most of them worried about the future of their family, and this caused anxiety and sleep disorders. For many of the male participants, getting married is especially important because it involves perpetuating the family line. Therefore, some sought advice before deciding to marry.

I went to my doctor and asked, "Dear sir, can I marry? Why should I cause trouble for another family?" The doctor told me, "Yes. I don't see any problem with you getting married. But you can also think about your life and ask what would happen later." Before marriage, I informed the woman who is now my wife... And now she, too, very well knows my pain. My only wish is to stay alive until we raise our children... [after a short silence] because when you bring children to the world, you should also consider their lives. Now, my only regret is having children in this world because children need both parents to grow up. MI:13

While none of the male participants were divorced, $30 \%$ of the female participants were divorced. The excerpts and statistics above demonstrate gendered lived experiences among survivors in Halabja. A female survivor is often divorced as soon as her husband or his family experiences $\mathrm{SM}$ effects.

I mean I even talked to them about my health condition. Later, when they knew this was my condition, they divorced me. FI:12

The majority of the male participants considered men to be the family breadwinners. They reported that they feared for the future for their families as their health deteriorated post exposure. Many men wondered what would happen if the husband or father died, or is disabled and can no longer sustain the family financially?

I cannot stop thinking that If I would get paralysed and must lie in bed for the rest of my life... who is, then, going to take care of my wife and children? MI:13

Many male participants also reported that post-exposure effects and psychological symptoms have affected their families and caused men to view themselves as a burden.

I don't know what kind of emotional and psychological change has taken root in me. I feel that I often become angry; I feel that my family is about to get fed up with me. MI:4

While male participants perceived SM exposure as having genetic effects and felt they had been contaminated, female participants identified themselves as actually being contaminated. These lived experiences are associated with a lack of societal understanding of women's health, which then impacts the possibility of marriage.

I feel that this effect is genetic. Let's say it [SM] has affected every single part of our bodies. I mean the chemicals have become part of our bodies. MI:5

It [SM] has affected our children too. Actually, now we... I have a 5 -year-old child who is deaf and an older daughter who also suffers from the chemicals. They say it is the effects of chemical weapons. It's yours, which transfers to your children. FI:13

Sexual satisfaction is generally perceived as an important component in a good marriage. Yet the majority of male participants experienced sexual dysfunction as a post-SM exposure condition and perceived it as a key factor behind their poor marital relations. Inquiring about sex as a non-confidant of the participant can be difficult, and women, in particular, did not feel comfortable discussing sex openly with a male researcher. However, it is clear that for women, marriage is the main way to have a socially sanctioned sexual relationship. In fact, healthy women who are married to male survivors also suffer the long-term impacts of CWAs.

When I sleep, I don't like anyone beside me. She [his wife] doesn't have a choice. Poor woman.... If she knew this was my situation and that I am so restless, so much crying all the time and my life is like this, she really wouldn't have married me.... MI:I

\section{DISCUSSION}

Challenges faced in social and private life following exposure to SM have only been discussed previously among male war veterans. ${ }^{29}$ To our knowledge, this is the first study to examine the lasting effects of SM on family and marriage among civilian survivors in Halabja.

\section{Main findings}

Uncertainty is a central, lively issue shaping the participants' lived experiences and narratives around the aftermath of the attack (figure 1). Survivors complain of symptoms that do not fit into currently accepted medical and psychiatric diagnostic categories. This is consistent with previous studies that report the emergence of postexposure undefined new health conditions, and sociogenic illness among survivors. ${ }^{30} 31$ Survivors often fear that their immune system has turned against them, which is reflected in bodily transformation post exposure. This comes alongside chemical contamination anxiety and 
all-encompassing uncertainty. ${ }^{17}{ }^{31}$ Phrases such as "I am afraid of getting married," "I am afraid of having children" and "It (CWA) will kill you certainly" are recurrent in the interviews. The participants' lived experience of social abandonment, stigma and everyday uncertainties as the result of SM lead to ethical dilemmas concerning living with others, taking partners and having children. This, in turn, leads to a condition where SM-exposed individuals, women in particular, are forced into dehumanising situations such as a slow social death long before their biological death. ${ }^{32}$

Knowledge about SM's adverse reproductive effects is still fuzzy, thus more studies are needed. ${ }^{20}$ Our analyses show that anxiety over SM impacts offspring, and fears of having a child with birth defects is a huge uncertainty related to marriage for SM survivors, regardless of gender. This stigma has had a devastating impact on female survivors in Halabja and is the main obstacle to their getting married, thus denying them a base for building their social life. As one of the female participants insisted, "Girls are only [worried] about one thing, that is, marriage." Using the medical diagnostic label of exposure to CWAs has created a destructive stigma which has both minimised female survivors' chances of marrying and excluded them from society. ${ }^{33}$ Likewise, chronic illness among other infectious diseases could be associated with social stigma, and women may be affected differently in these cases (ie, in terms of marriage prospects and social life limitations).$^{34}$ However, exposure to CWAs is unique in terms of exposure and chemical contamination anxiety. ${ }^{17}$

\section{Social abandonment}

An important finding of this study is the survivors lived experiences of social abandonment. Survivors avoid socialising because they feel they are disgusting to others who perceive post-exposure effects like an infectious or contagious disease. ${ }^{17} 29$

The post-exposure effects-physical, psychological, social and socioeconomic-increase in complexity over time and have left the survivors with a sense of uncertainty regarding their ability to support a family, have a successful marriage and contribute to society ${ }^{17}$ (figure 2).

The lack of public knowledge regarding SM effects has fueled social stigmatisation. ${ }^{17}$ Survivors do not participate in social events in order to avoid unfamiliar circumstances where others may not understand their post-exposure experiences. Although there is a shared public memory of the chemical bombardment on Halabja, survivors often come together in distinct social circles rooted in a set of shared lived experiences, both during the bombardment and post exposure. These shared lived experiences have fostered connections among them (ie, a collective experience of abandonment), formed a gendered condition and distanced them from the rest of society. Moreover, both women and men have developed an identity under the group label 'chemical weapons injured'. This mode of self-identification not only explicitly states that health is part of their identity but also draws political attention to their vulnerable condition. Their expressed experiences of social abandonment reflect both the lived experience of 'chemical weapons injured' and society's response to unknown CWAs-related health phenomena and, by extension, phenomena related to new, medically incurable diseases that subject survivors to social, economic, cultural and political exclusion, and thus dehumanisation. $^{32}$ 35-37

\section{Uncertain marriage}

Another finding of our study is how long-term effects of CWAs produce a gendered condition in which female and male survivors experience marriage differently. For many exposed men, their condition is a salient source of stress and suffering. Fear of death due to post-exposure effects, chemical contamination anxiety, reduced libido and socioeconomic destitution are major concerns among CWAs-exposed men, and this adversely impacts family and social life. ${ }^{1731}$ This has radically shifted men' feelings from the pride of being their families' breadwinners to shame of becoming a burden to their families. Interestingly, half of the male participants were unemployed. Many women also perceived exposure as a source of trauma, social insult, humiliation and psychological harm. Overall, $30 \%$ of the female participants were divorced, $40 \%$ were single and $70 \%$ were unemployed. This and other gender barriers leave SM-exposed women in an even more subordinate gender position than other women in the same social setting.

Participants' lived experiences show that while SM-exposed married men have a range of concerns and suffer in silence, SM-exposed women face divorce, experience cancelled engagements and live with several related uncertainties.

These conditions could be related to the diagnostic stamp of CWAs exposure and not even necessarily the post-exposure symptoms and are clearly gendered. Many female survivors are, rightly or wrongly, considered incapable of building a strong family life; as noted, only $20 \%$ of the female survivors were married. ${ }^{132638}$ It is important to note that this study focussed on female survivors of CWAs and not on conditions of women in the city as whole. Therefore, it does not deny contributions of women to the social and political formation of Halabja which dates back to Adela Khanem who ruled as the mayor between 1909 and $1924 .^{39}$ The current mayor of Halabja is also a woman.

Limitations of the study include that participants came from a war-ravaged environment, meaning their cumulative traumatic experiences may have affected the outcome. The gender of the interviewer might have hindered female interviewers' narrations of important lived experiences. However, the interviewer was also a medical doctor, which might have minimised the gender obstacle due to participants' trust in physicians. ${ }^{40}$

As outlined in figure 2, the lasting effects of CWAs on marriage and family have previously been neither evaluated scientifically nor addressed politically. Although they 
appeared within a few years after the attacks, this population's social challenges have continued to increase and become more complicated.

\section{CONCLUSION}

Our study opens novel gendered perspectives on marriage and family building among survivors of CWAs. Survivors have developed a manifest sense of gendered uncertainty about getting married, and exposure to CWAs has radically shifted their lives. This study also delineates the urgency of scientific intervention to improve social and family lives of survivors of CWAs, and push policymakers to address survivors' living conditions and the gender differential needs. Survivors of CWAs exposure should be provided with evidence-based consultancy to help them optimise their decision-making around marriage and family.

\section{Author affiliations}

${ }^{1}$ Occupational and Environmental Medicine, Institution of Medicine, Sahlgrenska Academy at University of Gothenburg, Gothenburg, Sweden

${ }^{2}$ Johannesburg Institute for Advanced Study, University of Johannesburg, Johannesburg, South Africa

${ }^{3}$ Department of Respiratory Medicine and Allergology, Institution of Medicine, Sahlgrenska Academy at University of Gothenburg, Gothenburg, Sweden

Acknowledgements We are grateful to all participants in this study. We would like to thank Dezgai Shahidan and the MMAA Bureau of Sulaymaniyah for their help, the non-governmental organisations-Halabja Chemical Victims' Society and Halabja Glory Organization-for facilitating the recruitment of participants, and Mr Goran Baba Ali for his help in the transcription and translation of the interviews.

Contributors FarM: Conceptualisation, data curation, methodology, validation, data analysis and interpretation, and writing — original draft. FazM: Methodology, validation, theoretical analysis and writing - review, editing and critical revision. MS: Critical revision, review and editing. A-CO: Read the final version of the manuscript. ML: Supervision, critical revision, review and editing.

Funding The study funded as part of a PhD thesis doctoral study grant (DOS) awarded to FarM by Region Västra Götaland, Närhälsan Research and Development Primary Health Care, Gothenburg. Project number: 272597.

Competing interests None declared.

Patient consent for publication Not required.

Ethics approval The study was approved by the ethical review board at the MMAA Bureau of Sulaymaniyah and by the Regional Ethical Review Committee in Gothenburg, Sweden.

Provenance and peer review Not commissioned; externally peer-reviewed.

Data availability statement Data are available upon reasonable request. The sharing of the data used in this study has been restricted because they contain sensitive, identifying information which is not possible to suitably anonymise for public sharing. Data can be made available upon request after any details that may risk the confidentiality of the participants have been removed. To request access to these data, please contact the corresponding author.

Open access This is an open access article distributed in accordance with the Creative Commons Attribution Non Commercial (CC BY-NC 4.0) license, which permits others to distribute, remix, adapt, build upon this work noncommercially, and license their derivative works on different terms, provided the original work is properly cited, appropriate credit is given, any changes made indicated, and the use is non-commercial. See: http://creativecommons.org/ licenses/by-nc/4.0/.

\section{ORCID iD}

Faraidoun Moradi http://orcid.org/0000-0002-8984-1660

\section{REFERENCES}

1 Jones E, Everitt B, Ironside S, et al. Psychological effects of chemical weapons: a follow-up study of first World War veterans. Psychol Med 2008;38:1419-26.

2 Eisenkraft A, Gilburd D, Kassirer M, et al. What can we learn on medical preparedness from the use of chemical agents against civilians in Syria? Am J Emerg Med 2014;32:186.

3 Ghanei M, Naderi M, Kosar AM, et al. Long-term pulmonary complications of chemical warfare agent exposure in Iraqi Kurdish civilians. Inhal Toxicol 2010;22:719-24.

4 Clarke SA, Weir AGA. UK resilience to a chemical incident. BMJ Mil Health 2020;166:95-8.

5 Moradi F. Genocide in translation: On memory, remembrance, and politics of the future. In: Moradi F, Buchenhorst R, SixHohenbalken M, eds. Memory and genocide: on what remains and the possibility of representation. London and New York: Routledge, 2017: 57-74.

6 Talabani JM, Ali Al, Kadir AM, et al. Long-Term health effects of chemical warfare agents on children following a single heavy exposure. Hum Exp Toxicol 2018;37:836-847.

7 Hay A, Roberts G. The use of poison gas against the Iraqi Kurds: analysis of bomb fragments, soil, and wool samples. JAMA 1990;263:1065a-6.

8 Macilwain C. Study proves Iraq used nerve gas. Nature 1993;363:3.

9 Hilterman J. A poisonous affair: America, Iraq, and the gassing of Halabja. Cambrige, Uk: Cambridge University Press, 2007.

10 Hashemian F, Khoshnood K, Desai MM, et al. Anxiety, depression, and posttraumatic stress in Iranian survivors of chemical warfare. JAMA 2006;296:560-6.

11 Wessely S, Hyams KC, Bartholomew R. Psychological implications of chemical and biological weapons. BMJ 2001;323:878-9.

12 Okcuoglu D. Choman Hardi. gendered experiences of genocide: anfal survivors in Kurdistan-Iraq. Int Fem J Polit 2013;15:131-2.

13 Moradi F, Sanford V. The force of writing in genocide: on sexual violence in the al-Anfal operations and beyond. In: Salvi CM, ed. Gender violence in peace and war: states of complicity. New Brunswick; London: Rutgers University Press, 2015: 102-15.

14 Dalaqua RH, Revill J, Hay A. Missing links: understanding sex- and gender-related impacts of chemical and biological weapons. UNIDIR, 2019.

15 Rowell M, Kehe K, Balszuweit F, et al. The chronic effects of sulfur mustard exposure. Toxicology 2009;263:9-11.

16 Balali-Mood M, Hefazi M. Comparison of early and late toxic effects of sulfur mustard in Iranian veterans. Basic Clin Pharmacol Toxicol 2006;99:273-82.

17 Moradi F, Söderberg M, Moradi F, et al. Health perspectives among Halabja's civilian survivors of sulfur mustard exposure with respiratory symptoms-A qualitative study. PLoS One 2019;14:e0218648.

18 Beigi Harchegani A, Mirnam Niha M, Sohrabiyan M, et al. Cellular and molecular mechanisms of sulfur mustard toxicity on spermatozoa and male fertility. Toxicol Res 2018;7:1029-35.

19 Panahi Y, Ghanei M, Ghabili K, et al. Acute and chronic pathological effects of sulfur mustard on genitourinary system and male fertility. Urol J 2013;10:837-46.

20 Soroush M, Modirian E, Khateri S. Long-term effects of exposure to mustard gas on male infertility. Iran Red Crescent Med $J$ 2008;10:344-5.

21 Khan F, Niaz K, Ismail Hassan F, et al. An evidence-based review of the genotoxic and reproductive effects of sulfur mustard. Arch Toxicol 2017;91:1143-56.

22 Ghanei M, Rajaee M, Khateri S, et al. Assessment of fertility among mustard-exposed residents of Sardasht, Iran: a historical cohort study. Reprod Toxicol 2004;18:635-9.

23 Graneheim UH, Lundman B. Qualitative content analysis in nursing research: concepts, procedures and measures to achieve trustworthiness. Nurse Educ Today 2004;24:105-12.

24 Sofaer S. Qualitative methods: what are they and why use them? Health Serv Res 1999;34:1101-18.

25 Hefazi M, Attaran D, Mahmoudi M, et al. Late respiratory complications of mustard gas poisoning in Iranian veterans. Inhal Toxicol 2005;17:587-92.

26 Moradi F, Buchenhorst R. Memory and genocide: on what remains and the possibility of representation. London and New York: Routledge, 2017.

27 Zamawe FC. The implication of using NVivo software in qualitative data analysis: evidence-based reflections. Malawi Med $J$ 2015;27:13-15.

28 Tong A, Sainsbury P, Craig J. Consolidated criteria for reporting qualitative research (COREQ): a 32-item checklist for interviews and focus groups. Int J Qual Health Care 2007;19:349-57. 
29 Hassankhani H, Taleghani F, Mills J, et al. The challenges experienced by Iranian war veterans living with chemical warfare poisoning: a descriptive, exploratory study. Scand J Caring Sci 2010;24:290-8.

30 Vyner HM. The psychological dimensions of health care for patients exposed to radiation and the other invisible environmental contaminants. Soc Sci Med 1988;27:1097-103.

31 Derges J. Impotent warriors: gulf war syndrome, vulnerability and masculinity, by Susie Kilshaw. Anthropol Med 2009;16:334-6.

32 João B. Vita: life in a zone of social abandonment Berkeley. University of California Press, 2005.

33 International A. "Clouds of injustice: Bhopal disaster 20 years on", 2004.

34 Jones WK, Weil D, Coreil J, et al. Stigma: lessons from Women1. Emerg Infect Dis 2004;10:e19.
35 Erving G. Stigma: notes on the management of spoiled identity London. Penguin Books, 1990.

36 Kleinman A, Eisenberg L, Good B. Culture, illness, and care: clinical lessons from anthropologic and cross-cultural research. Ann Intern Med 1978;88:251-8.

37 Kleinman A. The illness narrative: suffering, healing, and the human condition. New York: Basik Books, 1988.

38 Hardi C. Gendered experiences of genocide, Anfal survivors in Kurdistan-iraq. England: Ashgate publishing Limited, 2011.

39 Edmonds CJ, Kurds T. Politics, travel and research in north-eastern Iraq, 1919-1925. London, 1957.

40 Pearson SD, Raeke LH. Patients' trust in physicians: many theories, few measures, and little data. J Gen Intern Med 2000;15:509-13. 